\title{
Transurethral Resection of the Prostate for the Treatment of Lower Urinary Tract Symptoms Related to Benign Prostatic Hyperplasia: How Much Should Be Resected?
}

\author{
Alberto A. Antunes, Miguel Srougi, Rafael F. Coelho, Katia R. Leite, Geraldo de C. Freire
}

Division of Urology, University of Sao Paulo Medical School, Sao Paulo, SP, Brazil

\begin{abstract}
Objective: To assess the impact of the percent of resected tissue on the improvement of urinary symptoms.

Materials and Methods: The study included a prospective analysis of 88 men with benign prostatic hyperplasia. Patients were divided in three groups according to the percent of resected tissue: Group $1<30 \%$; Group 2, 30\% to $50 \%$; and Group $3,>50 \%$. Each patient was re-evaluated 3 months after surgery. We assessed the international prostatic symptom score, nocturia and serum prostate specific antigen levels.

Results: All patients presented a significant decrease on mean International Prostate System Score (IPSS) (23 to 5.9), Quality of Life (QoL) (4.9 to 1.0) and nocturia (3.2 to 1.9). Variation in the IPSS was 16.7, 16.6 and 18.4 for patients from Group 1,2 and 3 respectively $(\mathrm{P}=0.504)$. Although the three groups presented a significant decrease in QoL, patients in Group 3 presented a significantly greater decrease when compared to Group 1. Variation in QoL was 3.1, 3.9 and 4.2 for patients from Group 1, 2 and 3 respectively $(p=0.046)$. There was no significant difference in nocturia variation according to the percent of resected tissue $(\mathrm{p}=0.504)$. Median pre and postoperative PSA value was 3.7 and $1.9 \mathrm{ng} / \mathrm{mL}$ respectively. Patients from Group 1 did not show a significant variation $(\mathrm{p}=0.694)$. Blood transfusions were not required in any group.

Conclusions: Resection of less than $30 \%$ of prostatic tissue seems to be sufficient to alleviate lower urinary tract symptoms related to benign prostate hyperplasia. However, these patients may not show a significant decrease in serum PSA level.
\end{abstract}

Key words: prostate; benign prostatic hyperplasia; transurethral prostatectomy; symptom score; organ weight Int Braz J Urol. 2009; 35: 683-91

\section{INTRODUCTION}

Benign prostatic hyperplasia $(\mathrm{BPH})$ is the most common benign neoplasm in men. By the age of 60, half of all men have histological evidence of BPH and virtually all men have it by the age of 80 (1). Additionally, in a recent retrospective study of more than one million men 50 years of age or older in a managed care population from United States, BPH was among the four prevalent diagnoses (2).

Despite the development of new minimally invasive methods, transurethral resection of the pros- tate (TURP) remains the gold standard surgical treatment for lower urinary tract symptoms (LUTS) related to $\mathrm{BPH}$, with more than $90 \%$ of the patients reporting normal or improved voiding, after 10-year follow-up period $(3,4)$. The recommended technique of TURP consists of complete removal of all adenomatous tissue inside the surgical capsule (5). However, complication rates seem to be related to resection time and the amount of resected tissue (6), and historical data has shown that the amount of resected tissue during TURP has decreased significantly over the last 10 years $(7,8)$. 
In fact, to date there is no consensus regarding what amount of tissue should be resected during TURP. While some authors have suggested that better clinical results after TURP may correlate with the completeness of the resection of the obstructing adenoma $(9,10)$, others have shown that partial resection produces short-term functional results comparable to those of standard TURP $(11,12)$. The aim of this study was to evaluate the impact of the percent of resected tissue (PRT) during TURP on the short-term clinical outcome of patients with LUTS due to $\mathrm{BPH}$.

\section{MATERIALS AND METHODS}

The study comprised a prospective analysis of a cohort of 144 consecutive men who underwent TURP for treatment of LUTS due to BPH between February 2006 and June 2007. After exclusion of 56 cases that were treated for urinary retention, the final sample comprised of 88 patients. All these patients had moderate or severe LUTS that were refractory to medical treatment and were at least dissatisfied with their urinary condition. Patients with neurogenic bladder or prostatic carcinoma were not considered for analysis.

All patients underwent detailed physical examination including digital rectal examination, blood chemistry, urine analysis and serum prostate specific antigen (PSA) test. For assessment of LUTS and QoL, we used the International Prostate Symptom Score (IPSS) (13) and its appended 8th question related to quality of life (QoL). PSA behavior was also analyzed. Prostate volume was measured through abdominal ultrasound and estimated as length $\mathrm{x}$ width $\mathrm{x}$ height $x$ 0.52. All patients were operated on under spinal anesthesia with a 24-French Storz continuous-flow resectoscope and a standard loop. The resected tissue was systematically weighed immediately after the surgical procedure. Perioperative complications were recorded if present. The urethral Foley catheter was removed from all patients 48 hours after TURP and they were discharged home on the third postoperative day. They were re-evaluated at 3 months for LUTS, QoL, nocturia and serum PSA levels.

The PRT was calculated as the resected tissue weight divided by the preoperative ultrasound prostate volume measurement $x 100$. Patients were divided in three groups according to the PRT: Group $1<30 \%$; Group $2=30 \%$ to $50 \%$; and Group $3>50 \%$. Table- 1 shows the baseline demographic characteristics of the three study groups. Mean patient age, IPSS, nocturia, duration of symptoms, prostate weight and serum PSA levels were similar between the groups. Regarding QoL, patients from Group 3 presented a marginally significant higher mean score when compared to patients from Group 1.

Table 1 - Baseline characteristics of patients according to the percent of resected tissue.

\begin{tabular}{lcccc}
\hline & $\begin{array}{c}<\mathbf{3 0 \%} \\
(\mathrm{n}=23)\end{array}$ & $\begin{array}{c}\mathbf{3 0} \text { to } \mathbf{5 0 \%} \\
(\mathrm{n}=43)\end{array}$ & $\begin{array}{c}>\mathbf{5 0 \%} \\
(\mathrm{n}=22)\end{array}$ & p Value \\
\hline Age & $69.4 \pm 9.4$ & $66.1 \pm 8.3$ & $68.7 \pm 7.7$ & 0.254 \\
Preoperative prostate weight $(\mathrm{g})$ & $53.0 \pm 14.8$ & $53.8 \pm 13.5$ & $53.1 \pm 13.0$ & 0.971 \\
Mean IPSS & $24.4 \pm 6.6$ & $22.8 \pm 6.0$ & $24.7 \pm 5.7$ & 0.418 \\
Mean QoL score & $4.4 \pm 0.9$ & $4.9 \pm 1.0$ & $5.2 \pm 0.9$ & 0.056 \\
Mean nocturia & $3.5 \pm 1.4$ & $2.9 \pm 1.3$ & $3.4 \pm 1.9$ & 0.273 \\
Median preoperative PSA & 3.0 & 3.7 & 4.0 & 0.136 \\
(min - max) & $(0.5-10.0)$ & $(0.8-34.0)$ & $(1.4-14.0)$ & 0.719 \\
Median duration of symptoms & 3.0 & 3.0 & 2.5 & $(1-10)$ \\
(min - max days) & $(1-10)$ & $(1-15)$ & \\
\hline
\end{tabular}

IPSS = international prostate symptom score; $Q \mathrm{oL}=$ quality of life. 
Since for the patient the most important outcome parameter is satisfaction with symptomatic improvement, primary end point was a change in QoL score according to the PRT. Secondary end points were a change in IPSS, nocturia or serum PSA levels. For statistical analysis we used the ANOVA test. Statistical analysis was performed using the SPSS 12.0 for Windows software and significance was set as $\mathrm{p}$ $\leq 0.05$.

\section{RESULTS}

Mean resected tissue weight was $12.4 \pm 4.4$, $22.3 \pm 7.4$ and $33.8 \pm 6.1$ grams for patients from group 1, 2 and 3 respectively ( $<0.001)$. Mean pre and postoperative QoL score was $4.9 \pm 1.0$ and $1.0 \pm$ 1.0 respectively. The three groups showed a significant improvement in QoL (mean $3.7 \pm 0.3 ; \mathrm{p}<0.001$ ), however, patients from Group 3 when compared to patients from Group 1 presented a significantly greater decrease $(\mathrm{p}=0.046)$. Variation in QoL was $3.1 \pm 0.3$, $3.9 \pm 0.2$ and $4.2 \pm 0.3$ for patients from group 1,2 and 3 respectively (Figure-1).

Mean pre and postoperative IPSS was $23.0 \pm$ 5.6 and $5.9 \pm 4.6$ respectively. There was a significant decrease in IPSS among the three study groups (mean $17.1 \pm 0.7 ; \mathrm{p}<0.001)$, but despite a slight greater variation among patients from group 3 , no significant statistical difference in the IPSS variation according to the PRT was observed $(p=0.561)$. Variation in IPSS was $16.7,16.6$ and 18.4 for patients from group 1, 2 and 3 respectively (Figure-2).

Mean pre and postoperative nocturia was 3.2 \pm 1.5 and $1.9 \pm 1.3$ respectively. Again, the 3 groups presented a significant decrease in nocturia (mean 1.4 $\pm 0.2 ; \mathrm{p}<0.001)$. There was no significant difference in nocturia variation according to the PRT $(p=0.504)$. Postoperative nocturia was $1.8 \pm 1.3,1.7 \pm 1.4$ and 2.0 \pm 1.4 for patients from Group 1, 2 and 3 respectively (Figure-3).

Median pre and postoperative PSA value was $3.7 \mathrm{ng} / \mathrm{mL}(0.3$ - 24.8) and $1.9 \mathrm{ng} / \mathrm{mL}(0.2$ - 11.0) respectively. While patients from group 2 and 3 presented a significant drop in PSA levels $(\mathrm{p}=0.003$ and $p=0.002$ respectively), patients from Group 1 did not show a significant variation in PSA levels $(\mathrm{p}=$ $0.694)$. Median postoperative PSA levels were $2.4(0.2$ - 11.0), $1.4(0.4$ - 5.9) and 1.15 (0.3 - 5.4) for patients from Group 1, 2 and 3 respectively (Figure-4). Blood transfusions were not required in any group.

\section{COMMENTS}

The present study demonstrated that the amount of resected tissue seems to have little impact on the short-term clinical outcome after TURP. Al-

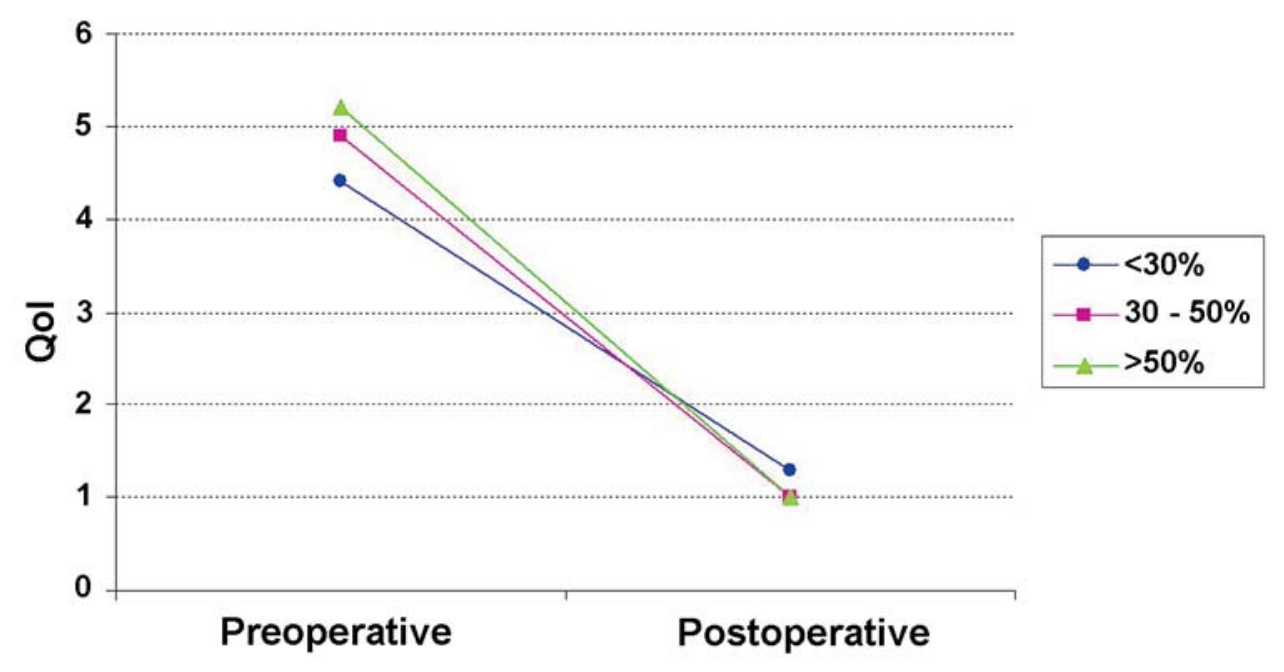

Figure 1 - Variation in quality of life (QoL) according to percentage of resected tissue. 


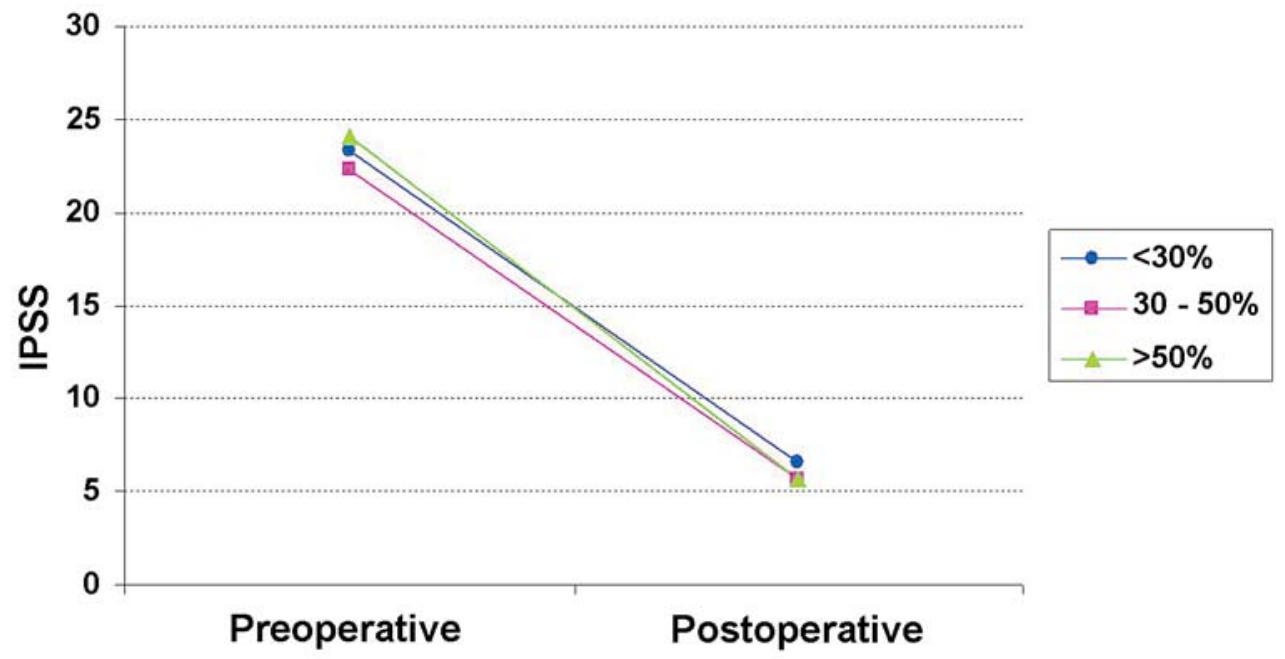

Figure 2 - Variation of International Prostate Symptom Score (IPSS) according to percentage of resected tissue.

though patients who had more than $50 \%$ of the prostatic tissue resected presented a significantly greater decrease in QoL score when compared to patients in Group 1, both groups presented a significant decrease when analyzed individually. Variations in IPSS were also slightly greater among patients from Group 3, but this figure was not statistically significant. Nocturia was not influenced by the PRT.

Despite the proven efficacy of TURP, the question of how much prostatic tissue should be resected has existed for more than 70 years. While McCarthy stated in 1931 that resection of median and lateral lobes should be performed until a free view into the bladder was obtained, Blandy stated in 1978 that total resection of the adenoma inside the surgical capsule between the bladder neck and the verumontanum was necessary (12).

The recommended TURP technique consists of complete removal of the entire adenoma inside the surgical capsule (5). However, when performed in

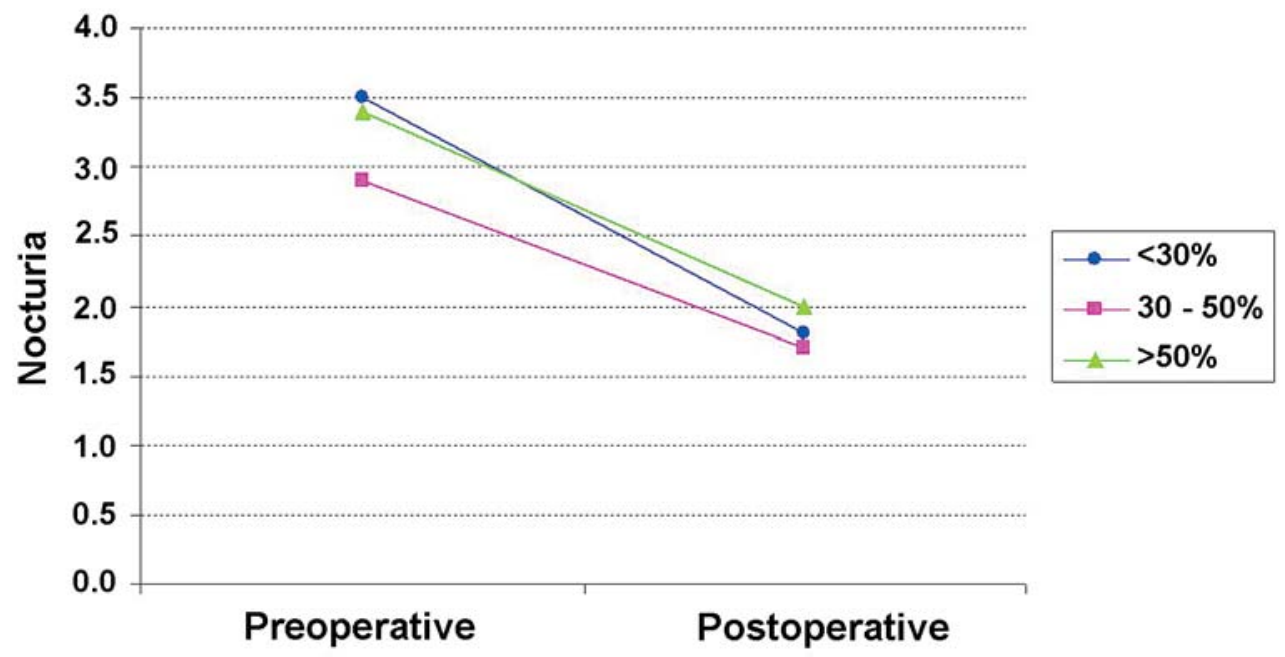

Figure 3 - Variation of nocturia according to percentage of resected tissue. 


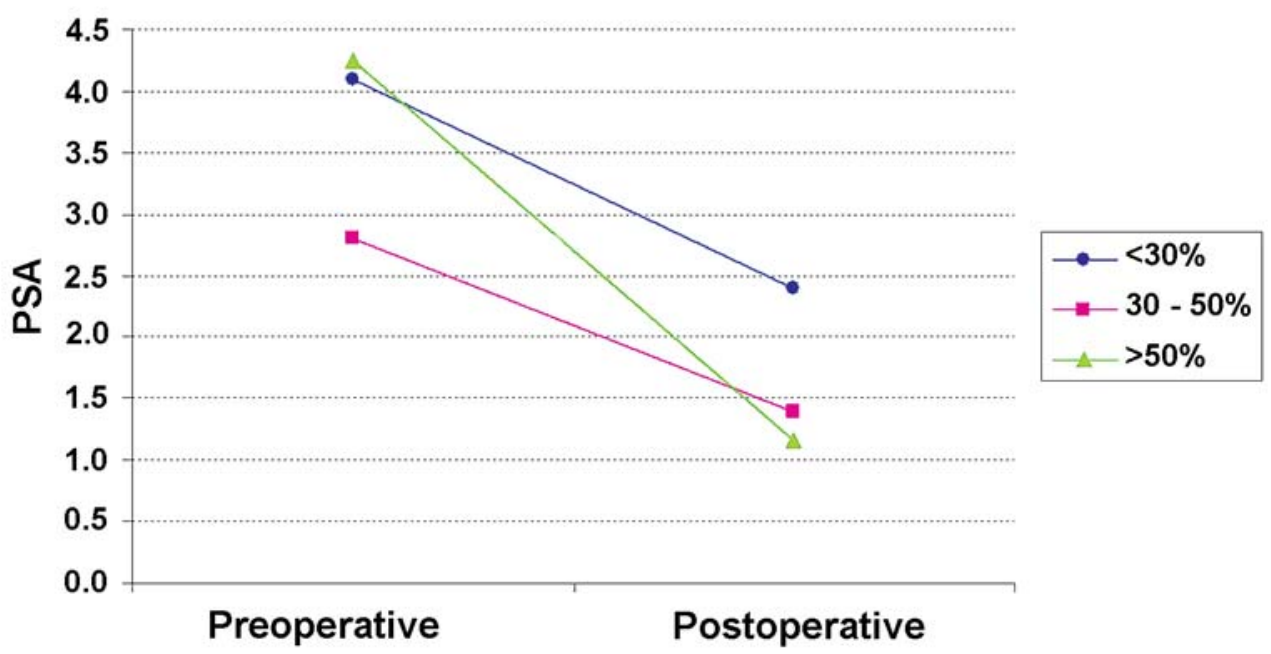

Figure 4 - Variation in PSA according to percentage of resected tissue.

medically compromised elderly patients with large prostates, this procedure may be associated with troublesome bleeding and irrigating fluid absorption leading to TURP syndrome. Data from 3861 consecutive patients with BPH who underwent TURP from 1971 to 1996 demonstrated that mortality, morbidity, and blood transfusions were observed in $0.1 \%, 13.4 \%$ and $13.1 \%$ patients, respectively. The most significant risk factors for blood transfusion were related to resection time, the amount of tissue resected, age, and the decade in which the surgery was performed (6). Regarding TURP syndrome, Mebust et al. (14), showed that its incidence was greater in resections lasting longer than 90 minutes and in those producing more than 45 grams of tissue. In the present series, $25 \%$ of the patients had more than $50 \%$ of the prostates resected, and no case required blood transfusions or developed TURP syndrome.

To date, there is still no consensus regarding the amount of prostatic tissue that should be resected during TURP. Despite the initial recommendations by Nesbit (5), historical data has shown that the amount of resected tissue has decreased significantly over time $(7,8)$. In the study of Borth et al. (7), mean weight of tissue resected in 1988 was $16.5 \mathrm{~g}$ and decreased to $12.5 \mathrm{~g}$ in 1998 . In the series of VelaNavarrete et al. (8), mean volume resected in 1992 was $35.7 \mathrm{~mL}$ and decreased to $24.3 \mathrm{~mL}$ in 2002 . In the series of Green et al. (15), which analyzed 432 patients who underwent TURP, the mean weight of tissue resected was $25.6 \mathrm{~g}$ and no surgeon resected more than $50 \%$ of the gland volume. In the present series the mean resected tissue weight was $22.3 \pm 10.2$ grams, which corresponded to a mean $42 \%$ of PRT.

Data analyzing the outcome of patients who underwent complete or partial TURP have led to controversial results. In the study of Chen et al. (9), these authors found a good relationship between residual prostate weight ratio (weight after TURP divided by the preoperative prostate weight) and clinical outcome variables among 40 patients who underwent TURP and were followed-up for 16 weeks. Their results suggest that the better clinical results after TURP correlate significantly with the completeness of the resection of the obstructing adenoma.

Conversely, Aagaard et al. (11) prospectively assessed the long-term results of total TURP and minimal TURP in 167 patients with obstructive symptoms caused by BPH and found that a significant relief in obstructive and irritative symptoms was observed in both groups. Maximum flow rate and post-void residual urine improvement were also similar between the groups. Similarly, more recently, Agrawal et al. (12), in a prospective and randomized study compared the hemiresection (complete resection of one lateral lobe and the median lobe, if present) of the prostate to the standard TURP. They found that the 2 groups had comparable improvement in symptom scores and 
flow rates. Two patients required blood transfusions and two developed TURP syndrome in the standard resection group and no complications were observed in the hemiresection group.

PSA behavior after TURP is crucial during patient follow-up and a subsequent rise in PSA may indicate prostate biopsy. Studies have shown that PSA decreases drastically in patients who undergo TURP. Fonseca et al. (16), showed that mean PSA levels declined $71 \%$ after TURP, and 60 days after surgery the reduction reached its peak, stabilizing afterwards. Mean PSA varied from $6.1 \mathrm{ng} / \mathrm{mL}$ before surgery to $1.7 \mathrm{ng} / \mathrm{mL}$ after 60 days postoperatively. In the present series we demonstrated that the amount of resected tissue might significantly influence PSA reduction. Variation in PSA among patients who had less than $30 \%$ of prostate resected was not significant and median postoperative PSA in this group was 2.4 $\mathrm{ng} / \mathrm{mL}(0.2-11.0)$. Urologists must take into account the PRT when analyzing the serum PSA in patients who have undergone TURP.

Some methodological limitations of the present study must be considered. We did not analyze LUTS function through objective measurements such as flow rates or residual urine. According to the American Urological Association guidelines these are optional assessments for patients with BPH who are candidates for surgical treatment (17). Follow-up was limited, however, the scope of the study was to assess symptom relief and previous data have suggested that no further symptom improvement would be observed after 3 months of TURP (10). Finally, prostate volume was measured by suprapubic rather than transrectal ultrasound. However, while the transuretral route is considered to be more accurate in prostate size determination, similar limitations exist for both methods (18).

\section{CONCLUSIONS}

Resection of less than $30 \%$ of prostatic tissue seems to be sufficient to alleviate LUTS related to BPH. However, these patients may not show a significant decrease in the serum PSA level. Analysis of PSA in men who have undergone TURP must take into account the PRT. Patients with more than 50\% of resected tissue may present a greater variation in QoL scores.

\section{CONFLICT OF INTEREST}

None declared.

\section{REFERENCES}

1. Berry SJ, Coffey DS, Walsh PC, Ewing LL: The development of human benign prostatic hyperplasia with age. J Urol. 1984; 132: 474-9.

2. Issa MM, Fenter TC, Black L, Grogg AL, Kruep EJ: An assessment of the diagnosed prevalence of diseases in men 50 years of age or older. Am J Manag Care. 2006; 12(4 Suppl): S83-9.

3. Rassweiler J, Teber D, Kuntz R, Hofmann R: Complications of transurethral resection of the prostate (TURP)--incidence, management, and prevention. Eur Urol. 2006; 50: 969-79; discussion 980.

4. Thomas AW, Cannon A, Bartlett E, Ellis-Jones J, Abrams P: The natural history of lower urinary tract dysfunction in men: minimum 10-year urodynamic followup of transurethral resection of prostate for bladder outlet obstruction. J Urol. 2005; 174: 1887-91.

5. Nesbit RM: Transurethral prostatic resection. In: Campbell L, Harrison J (ed.), Urology. Philadelphia, Sounders. 1970; pp. 2479.

6. Uchida T, Ohori M, Soh S, Sato T, Iwamura M, Ao T, et al.: Factors influencing morbidity in patients undergoing transurethral resection of the prostate. Urology. 1999; 53: 98-105.

7. Borth CS, Beiko DT, Nickel JC: Impact of medical therapy on transurethral resection of the prostate: a decade of change. Urology. 2001; 57: 1082-5; discussion 1085-6.

8. Vela-Navarrete R, Gonzalez-Enguita C, Garcia-Cardoso JV, Manzarbeitia F, Sarasa-Corral JL, Granizo JJ: The impact of medical therapy on surgery for benign prostatic hyperplasia: a study comparing changes in a decade (1992-2002). BJU Int. 2005; 96: 1045-8.

9. Chen SS, Hong JG, Hsiao YJ, Chang LS: The correlation between clinical outcome and residual prostatic weight ratio after transurethral resection of the prostate for benign prostatic hyperplasia. BJU Int. 2000; 85: 79-82.

10. Hakenberg OW, Helke C, Manseck A, Wirth MP: Is there a relationship between the amount of tissue 
removed at transurethral resection of the prostate and clinical improvement in benign prostatic hyperplasia. Eur Urol. 2001; 39: 412-7.

11. Aagaard J, Jonler M, Fuglsig S, Christensen LL, Jorgensen HS, Norgaard JP: Total transurethral resection versus minimal transurethral resection of the prostate-a 10-year follow-up study of urinary symptoms, uroflowmetry and residual volume. Br J Urol. 1994; 74: 333-6.

12. Agrawal MS, Aron M, Goel R: Hemiresection of the prostate: short-term randomized comparison with standard transurethral resection. J Endourol. 2005; 19: 868-72.

13. Barry MJ, Fowler FJ Jr, O'Leary MP, Bruskewitz RC, Holtgrewe HL, Mebust WK, et al.: The American Urological Association symptom index for benign prostatic hyperplasia. The Measurement Committee of the American Urological Association. J Urol. 1992; 148: 1549-57; discussion 1564.

14. Mebust WK, Holtgrewe HL, Cockett AT, Peters PC: Transurethral prostatectomy: immediate and post- operative complications. a cooperative study of 13 participating institutions evaluating 3,885 patients. 1989. J Urol. 2002; 167: 999-1003; discussion 1004.

15. Green JS, Bose P, Thomas DP, Thomas K, Clements $\mathrm{R}$, Peeling WB, et al.: How complete is a transurethral resection of the prostate? Br J Urol. 1996; 77: 398400.

16. Fonseca RC, Gomes CM, Meireles EB, Freire GC, Srougi M: Prostate specific antigen levels following transurethral resection of the prostate. Int Braz J Urol. 2008; 34: 41-8.

17. AUA Practice Guidelines Committee: AUA guideline on management of benign prostatic hyperplasia (2003). Chapter 1: Diagnosis and treatment recommendations. J Urol. 2003; 170: 530-47.

18. Matthews GJ, Motta J, Fracehia JA: The accuracy of transrectal ultrasound prostate volume estimation: clinical correlations. J Clin Ultrasound. 1996; 24: 5015.
Accepted after revision:

June 3, 2009

\section{Correspondence address:}

Dr. Alberto Azoubel Antunes

Rua Barata Ribeiro, 490 / 76

Sao Paulo, 01308-000, Brazil

Fax: +55 11 3255-6372

Email: antunesuro@uol.com.br

\section{EDITORIAL COMMENT}

Antunes and coauthors investigated the impact of the percent of resected tissue (PRT) on the improvement of lower urinary tract symptoms (LUTS). They found that resection of less than 30\% of prostatic tissue was sufficient to alleviated LUTS although a significant variation on PSA levels was not observed in this group. From the perspective of subjective outcome, the authors' observations indicate that symptom improvement can be achieved regardless of the PRT.

I do not believe that LUTS is always due to enlarged prostate. I do believe that LUTS does not need to always be related to prostate enlargement. For example, Asian men have a similar frequency of prostatic obstruction and more severe symptoms despite having a smaller prostate volume $(1,2)$. Thus, there is some reason in authors' results. However, since the authors could not provide objective data such as maximum flow rate, post-void residual, frequencyvolume charts, it is unknown whether these objective parameters may also be improved regardless of the PRT. In addition, we cannot know the lower limit of PRT for alleviating LUTS based on authors' results. Furthermore, although TURP is a truly ablative pro- 
cedure for obstruction, authors did not perform pressure-flow studies. Thus, we do not know how many patients who have detrusor underactivity or bladder outlet obstruction were included in this study.

In summary, the value of the findings of Antunes and co-authors remain unknown. Therefore, further studies are needed to answer the question about the PRT for the improvement of LUTS/BPH and its possible mechanism.

\section{REFERENCES}

1. Choi J, Ikeguchi EF, Lee SW, Choi HY, Te AE, Kaplan SA: Is the higher prevalence of benign prostatic

\section{EDITORIAL COMMENT}

In this paper Antunes et al. address the correlation between the amount of resected tissue during transurethral resection of the prostate (TURP) for benign prostatic hyperplasia (BPH) and the outcome of the procedure. Their conclusions are that "resection of less than $30 \%$ of prostatic tissue seems to be sufficient to alleviate lower urinary tract symptoms (LUTS) related to BPH".

On one hand, our classical idea of TURP is as much as complete removal of adenomatous tissue, mimicking an open simple prostatectomy, especially when operating on healthy patients without high surgical risk. On the other hand, the concept by Antunes et al. might sound really appealing because it obviously means reduced operative time and operative risks, as we all know that complications of TURP are related to the duration of the procedure, and it also means expanding indications of TURP to larger prostates.

However, we think that their final message can be misleading and the results have to be critically analyzed as the study suffers from some major methodological flaws. hyperplasia related to lower urinary tract symptoms in Korean men due to a high transition zone index? Eur Urol. 2002; 42: 7-11.

2. Tsukamoto T, Kumamoto Y, Masumori N, Miyake H, Rhodes T, Girman CJ, et al.: Prevalence of prostatism in Japanese men in a community-based study with comparison to a similar American study. J Urol. 1995; 154: 391-5.

Dr. Jae-Seung Paick Department of Urology Seoul National University Hospital Seoul, Korea E-mail: jspaick@snu.ac.kr

Regarding the study rationale: how can you offer patients a procedure that is planned as "incomplete" from the beginning; how do you inform the patients, in this series who are not too old and probably have a low ASA score, about the procedure?

The authors divided their patients in 3 cohorts according to the amount of resected tissue. Unfortunately, from a methodological point of view, this was the result of a retrospective analysis, while they ought to stratify and then randomize the patients preoperatively. Moreover, the operator should know exactly when to stop before beginning the procedure not while operating. As no selection criteria are reported one can imagine that the operator decided arbitrarily to stop the resection based on personal experience. However, TURP is the gold standard in surgical treatment of $\mathrm{BPH}$ because the technique has been standardized following specific anatomic landmarks so that results among different centers can be compared.

Which patient would benefit from a less than $30 \%$ TURP? Will we ever be able to understand when $30 \%$ (of adenomatous tissue or of the whole gland?) has been resected? How will we teach trainees to stop 
resection in order to gain good functional results? In our personal experience we had, of course, cases where we had to stop resecting because extensive blood loss or general perioperative complications occurred. And most of them functionally did fairly well afterwards.

As recognized by the authors themselves, objective outcome parameters, i.e. maximum urinary flow rate (Qmax) and post voiding residual urine volume (PRV), are missing here. Actually, it is suggested by some authors that a pressure/flow study had to be done when acting within the framework of a clinical trial. Moreover, the follow-up ( 3 months) is really too short here (also considering from current literature long-term data are already available for TURP). And the problem is not that, as the authors commented, "no further improvement might be observed...". In contrast, a worsening of the symptoms can be observed. That is why long-term data are needed when evaluating any new minimally invasive surgical procedure for BPH treatment.

In conclusion, we completely agree that "for the patient the most important parameter is satisfaction with the symptomatic improvement". This is the reason why we will continue to perform and to teach a complete TURP until a reproducible "mini-TURP" technique is established.

Dr. Riccardo Autorino \& Dr. Marco De Sio

Clinica Urologica Seconda Università degli Studi Napoli, Italy E-mail: ricautor@tin.it 